\title{
The Psychological Distress of Patients with Breast Cancer at University Teaching Hospital of Brazzaville
}

\author{
Judith Nsondé Malanda ${ }^{1,}$, , Freud Loukibou Ngouari ${ }^{1}$, Bab Salam Ngouaka ${ }^{2}$, \\ Siméon Stéphane Moubié ${ }^{3}$ \\ ${ }^{1}$ Oncology Service University Teaching Hospital, Brazzaville, Congo \\ ${ }^{2}$ Oncology Service Makelekele Hospital, Brazzaville, Congo \\ ${ }^{3}$ Oncology Service Central Army Hospital, Brazzaville, Congo
}

Email address:

drjmalandam@yahoo.fr (J. N. Malanda)

*Corresponding author

\section{To cite this article:}

Judith Nsondé Malanda, Freud Loukibou Ngouari, Bab Salam Ngouaka, Siméon Stéphane Moubié. The Psychological Distress of Patients with Breast Cancer at University Teaching Hospital of Brazzaville. International Journal of Clinical Oncology and Cancer Research. Vol. 6, No. 1, 2021, pp. 22-32. doi: 10.11648/j.ijcocr.20210601.14

Received: January 9, 2021; Accepted: January 16, 2021; Published: January 25, 2021

\begin{abstract}
Introduction the breast cancer affects all aspects of the patient's life. To assess the psychological of patients with breast cancer at University Teaching Hospital of Brazzaville. It is a transversal study carried out in the carcinology service of University Teaching Hospital of Brazzaville. The data collection took place in face-to-face mode into 2 stages; the first is a census of patients with breast cancer diagnosis showed to anatomy-pathology. The second is an individual interview on an epidemiological survey, clinical and therapeutic; then a survey on psychological distress on anxiety, depression and self-esteem. It took place from $1^{\text {st }}$ January 2019 to $31^{\text {st }}$ august 2019. One hundred and fifty (150) patients were quested. The Epi.info software and SPSS 25 allowed the data analysis. It was a cohort mostly formed with women (96\%) The patients of middle age was 50.14 (utmost from 21 to 28 years old). The prevalence of psychological distress was $82 \%$, depression and anxiety respectively; then $38 \%$ of patients showed a very week self-esteem. The associated factors with distress were: the developed stage of breast cancer (metastasis), side effects, aftermath related to the treatments, problems faced. It stands out that breast cancer has an aftereffect on psychological sphere of patients with breast cancer, showing an increase of psychological distress, anxiety, depression, together with the loss of self-esteem.
\end{abstract}

Keywords: Breast Cancer, Psychological Distress, Anxiety, Depression, Self-esteem

\section{Introduction}

Breast cancer affects all aspects of patient's life, people with cancer can feel all kind of emotion or they can have different reactions relative to the new reality [1]. The literature data reveals $30-40 \%$ of patients with breast cancer showing a significant psychological distress, therewith can contribute to an increase of physical morbidity and mental, as far as a poor quality's life $[2,3]$.

In our context, this aspect is often overlooked in care of delivery, which explains the non-feasibility of studies on this discipline in our countries. It is in this context that we carried out this study in order to assess the psychological distress of patients with breast cancer at University Teaching Hospital of
Brazzaville.

\section{Patients and Methods}

It was a transversal study, analytical to the prospective data collection which took place from $1^{\text {st }}$ January to $31^{\text {st }}$ August 2019 (08 months). Every patient showed with breast cancer is followed in the service (hospitalization or outpatient).

Were including in patients' study:

a) aged at least of 18 years old, regardless of sex or gender;

b) followed in the service for a period upper to 3 months;

c) which breast cancer diagnosis was made under the basic clinical argument and anatomy pathologic;

d) an effective status of WHO to 1 or 2 ; 
e) having their lighted consent to participate to the study.

Were not included in patients' study:

a) showing another cancerous pathology than breast;

b) unable to answer quiz;

c) having an altered general state $\mathrm{WHO} \geq 3$;

d) non-followed in the service;

e) having removed their lighted consent after initially giving it.

\subsection{Data Collection}

It was in face-to-face manner using a survey sheet wrote in French language, and translated into local tongue. Made in 2 stages:

a) the census of patients, was carried out in the service;

b) during individual interview, the patients were aware of data operation as regards.

The individual interview was carried out following:

a) an epidemiological survey: which allows, after getting the written census of patients, in order to get information on gender, birthdate, socioeconomic standard, religion, educational standard, marital status;

b) a clinical survey: by questioning, in order to get clinical variables, discovery circumstances, backgrounds. The physical examination in order to get anthropometrical parameters, tumor characteristics.

c) a survey on psychological distress: which allows the screening through a digital visual scale called "distress thermometer" from 0 to 10 , the value 10 being highest. This thermometer was designed by the NCCN (National Comprehensive Cancer Network) in 2009 and allows the psychological distress assessment in graphical manner to cancerous patients. This assessment corresponds to the distress felt by the patient during the last week including the day where the detection was made.

d) the French translation of this scale determines the step of 3 , the presence of a psychological pathological distress, a score included between 3 and 5 is a light psychological distress, a score between 6 and 7 is a middle psychological distress, a score between 8 and 10 is a serious psychological distress [4].

The distress thermometer is used together with "the list of problems faced".

This list of problems faced formed with 25 items divided into 6 dimensions (practice, spiritual, social/family, emotional, information, physics). Then, the list helps us to get information on a wide range of problems or anxieties associated with cancer [4].

survey on self-esteem: which has been assessed through Rosenberg scale self-esteem. It is a self-assessment which has 10 items (demonstrated by Morris Rosenberg in 1965), the French adaptation made in 1992 by Chambon. And about the quiz, it is formed of 10 items which 5 assesses positive self-esteem and others negative self-esteem. The answer differs according to Likert type scale in four points from "entirely disagreement" (1) to "entirely agreement" (4). The score that we get is by addition of scores to questions $1,2,4$,
6 and 7. As for questions 3, 5, 8, 9 and 10, the quotation is reversed. Then the score is included between 10 and 40 .

The results performance is both the same as man and woman [6]:

a) a lower score of 25 is a very weak self-esteem;

b) a score included between 25-31 is a weak self-esteem;

c) a score included between 31-34 is a middle self-esteem;

d) a score between 34-39 is a strong self-esteem;

e) a score greater than or equal to 39 is a very strong selfesteem.

However, concerning the non-literate participants, the selfquiz was made in local tongue.

\subsection{The Study Progress}

After the selection, patients were in consultation room, we briefly explained them the study, its objectives and its progress. After the census form signature, giving their agreement, we performed the clinical examination, which allows to get sociodemographic data, the circumstances discoveries together with backgrounds. The physical examination recorded the anthropometrical parameters, the senological examination and other machines in terms of call signs.

The scale on psychological distress coupled with problems faced, together with the self-quiz on anxiety and depression (HADS), and on Rosenberg self-esteem were filled out by the patients answering to all self-quiz to all items.

\subsection{The Variables of Study}

a) sociodemographics;

b) clinics (tumoral characteristics);

c) morphologics;

d) therapeutics: medical treatments, surgical, radiotherapy;

e) the psychological distress: a psychological distress score greater than or equal to 3 was considered, psychological pathological distress; the scores of different dimensions of the list of the associated problems - scores of sub-scale of anxiety and depression;

f) self-esteem: score of different constitutive items of selfesteem scale.

\subsection{Operational Definitions}

1. the distress in cancerology

According to National Comprehensive Cancer Network, distress is defined as "an unpleasant emotional experience and multidimensional of psychological nature (cognitive, behavioral, emotional) social and/or spiritual which interferes with the capacity to face up to cancer, its physical symptoms and its treatments".

Manifestations in the form of sadness and fear to the invalidating problems, such as the depression, anxiety, panic, social isolation together with existential spiritual crisis [5].

2. standard/socioeconomical status

It is an assessment concept, which concerns at the same time social and economic domain with their different 
relations. The measure of socioeconomical standard remains difficult, the multidimensional concept requires the use of several indicators. Here are the most useful indicators of socioeconomical status:

a) the education (instruction level);

b) the profession;

c) the income.

\subsection{The Judgment Criteria}

The assessment of degree and severity distress was made from the following scales: the thermometer of psychological distress coupled with the list of the associated problems, the Hospital Anxiety and Depression Scale (HADS) and the Rosenberg self-esteem scale.

a) about the thermometer of psychological distress, we divided the scores in the following manner: from 0 to 2 no psychological distress; from 3 to 5 , light psychological distress; from 6 to 7 , middle psychological distress; from 8 to 10 serious psychological distress;

b) about $H A D S$, a score less than or equal to 7 to the subscale of anxiety or depression: absence of anxious troubles or depressive; a score between 8 to 10 ; a score greater than or equal to 11: anxious trouble or similar depressive.

c) about Rosenberg self-esteem scale, the division of scale is the following: a lower scale to 25 within a very weak self-esteem, a score between 25 and 31: a weak selfesteem, a score between 31 to 34: a middle self-esteem, a score between 34 and 39: a score self-esteem, a greater than or equal to 39: a very strong self-esteem.

\subsection{The Statistical Analysis}

The data of this study were typed on an input mask created on Epi.info 7.2 software, data treatments were performed with Excel 2013. Concerning the statistical analysis, we used two software especially Epi.info 7.2 and SPSS 25.

The Pearson coefficient helped us to make the study between the distress scale and those of anxiety with also the depression.

The test of Chi-square of Pearson was used to study the link between the distress level and other variables; the test of Fisher was used when at least an effective theory was lower to 5 .

In order to identify the associated factors with distress after adjustment on other factors, a logistical regression was used. We included all factors having a p-value less than or equal to $20 \%$ in the model of logistical regression.

We indeed used odds ratio with its confidence interval to $95 \%$ as estimative parameter. The interval link was significant when the confidence interval did not include the value 1 . The great significance was at $5 \%$.

\subsection{Ethical Considerations}

The study was made in the anonymity respect and privacy of patients.

\section{Results}

a) selection of patients and the study population;

b) in the altogether, 150 patients answered to the selection criteria were finally included in the study.

Table 1. Socio-demographical character of the study of the population.

\begin{tabular}{lll}
\hline \multicolumn{2}{l}{ Socio-demographical character } & \\
\hline Gender & Effectives & Rate \\
\hline Women & 144 & $96 \%$ \\
Men & 6 & $4 \%$ \\
Age group (years) & & \\
[21-36] & 14 & $9.3 \%$ \\
[37-50] & 63 & $42 \%$ \\
[51-66] & 62 & $41.23 \%$ \\
Upper 66 & 11 & $7.3 \%$ \\
Religion & & \\
Christian & 144 & $96 \%$ \\
Non-christian & 6 & $4 \%$ \\
Education level & & \\
University & 47 & $31.3 \%$ \\
Secondary & 64 & $42.67 \%$ \\
Primary & 30 & $20.00 \%$ \\
Off school & 9 & $5.00 \%$ \\
Marital status & & \\
Single & 18 & $12.00 \%$ \\
Couple & 98 & $65.30 \%$ \\
Divorced & 12 & $8.00 \%$ \\
Widower & 22 & $14.67 \%$ \\
Total & $\mathbf{1 5 0}$ & \\
\hline
\end{tabular}

Table 2. Clinical characters of patients.

\begin{tabular}{|c|c|c|}
\hline Circumstances of discovery & Effectives & Percentage \\
\hline Nodule & 133 & 88.67 \\
\hline Orange skin & 56 & $37.33 \%$ \\
\hline Mammelonnaire flow & 16 & $10.67 \%$ \\
\hline Hemorrhagical ulceration & 21 & $14.00 \%$ \\
\hline Adenopathy & 25 & $16.67 \%$ \\
\hline \multicolumn{3}{|l|}{ Comorbidities } \\
\hline HIV & 2 & \\
\hline HBP & 27 & $18 \%$ \\
\hline Asthma & 2 & \\
\hline \multicolumn{3}{|l|}{ Body Mass Index (BMI) } \\
\hline$<18.5$ & 11 & $13.75 \%$ \\
\hline $18.5-24.99$ & 75 & $50 \%$ \\
\hline $25-29.99$ & 45 & $30 \%$ \\
\hline$\geq 30.00$ & 19 & $12.67 \%$ \\
\hline \multicolumn{3}{|l|}{ Tumor size (S) } \\
\hline S1 & 4 & $2.7 \%$ \\
\hline S2 & 30 & $20 \%$ \\
\hline S3 & 27 & $18 \%$ \\
\hline S4 & 73 & $48.7 \%$ \\
\hline Tx & 16 & $10.6 \%$ \\
\hline \multicolumn{3}{|l|}{ Metastasis } \\
\hline Lungs & 12 & $28.57 \%$ \\
\hline Liver & 7 & $16.67 \%$ \\
\hline Bones & 14 & 13.33 \\
\hline Controlateral breast & 2 & $4.7 \%-$ \\
\hline Pleura & 5 & $11.90 \%$ \\
\hline
\end{tabular}

\subsection{Socio-demographical Character}

Age: the middle age of patients was: $50,14 \pm 10,75$ (extremes of 21- 82 years).

The division of patients according to the age group is 
illustrate in table 1.

\subsection{Clinical Characters}

The division of patients according to the clinical characters is represented in table 2 .

\subsection{Therapeutical Characters}

The therapeutical characters are represented in table 3.

Table 3. Division of patients depending the received treatment.

\begin{tabular}{lll}
\hline Means & Effectives & Percentage (\%) \\
\hline Chemotherapy & 129 & $86 \%$ \\
Surgery & 88 & $58.6 \% 58.6 \%$ \\
Radiotherapy & 15 & $10.00 \%$ \\
Side effects & & \\
Nausea /vomit & 77 & $56.20 \%$ \\
Anemia & 25 & $18.25 \%$ \\
Liver failure & 09 & $6.57 \%$ \\
Alopecia & 112 & $81.75 \%$ \\
Lymphedema & 12 & $8.56 \%$ \\
Post-operative chest pain & 105 & $76.64 \%$ \\
\hline
\end{tabular}

\subsection{Distress Assessment of Patients}

The following board represents the psychological distress of patients.

Table 4. Division of patients according to the score level of psychological distress.

\begin{tabular}{lll}
\hline Distress level & Effective & Percentage (\%) \\
\hline $0-2$ & 27 & 18.00 \\
$3-5$ & 67 & 44.67 \\
$6-7$ & 38 & 25.33 \\
$8-10$ & 18 & 12.00 \\
Total & 150 & 100.00 \\
\hline
\end{tabular}

\subsubsection{Preoccupations/Problems Faced with Patients}

The figure 1, represent different size.

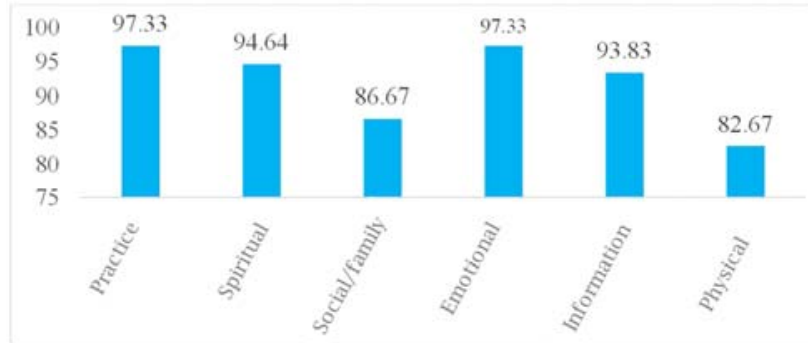

Figure 1. Distribution of patients according to the categories with problems faced.

\subsubsection{Practice Dimension}

The figure 2, shows different preoccupations on practice dimension.

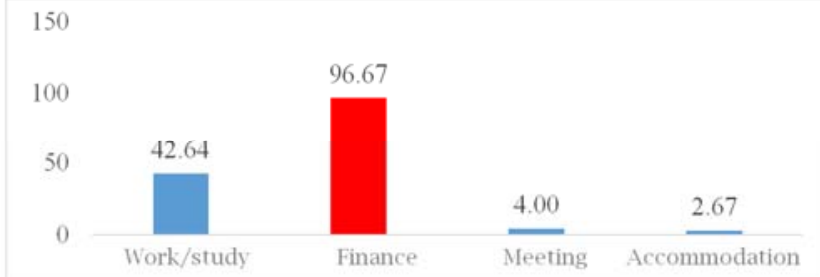

Figure 2. Distribution of patients according to the problems of practice dimension.

\subsubsection{Spiritual Dimension}

The figure 3, shows different preoccupations on spiritual dimension.

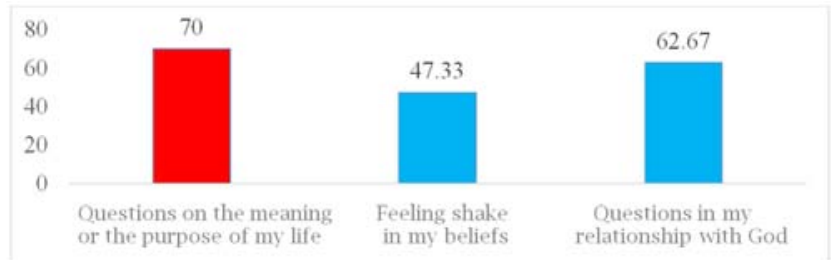

Figure 3. Distribution of patients according to the problems of spiritual dimension.

\subsubsection{Social/Family Dimension}

The figure 4 represents the different preoccupations on social/family dimension.

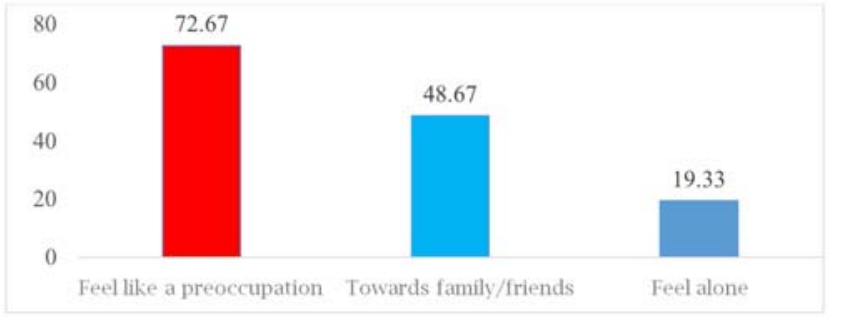

Figure 4. Distribution of patients, according to the social/family dimension.

\subsubsection{Emotional Dimension}

The figure 5 presents different preoccupations on emotional dimension.

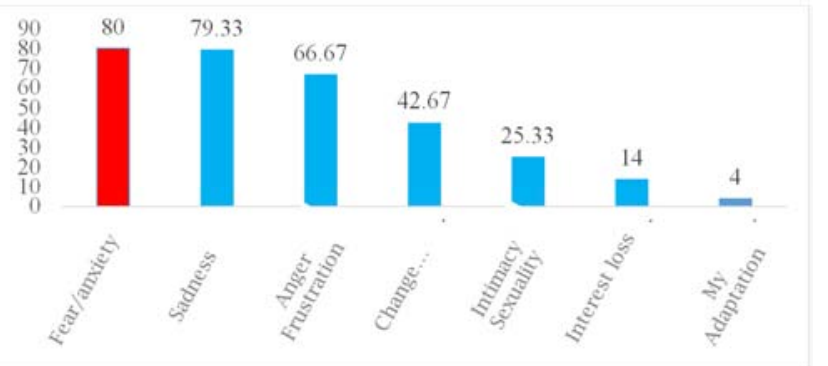

Figure 5. Distribution of patients according to the problems of emotional dimension.

\subsubsection{Information/Communication Dimension}

The figure 6 shows the different preoccupations on information/communication dimension. 


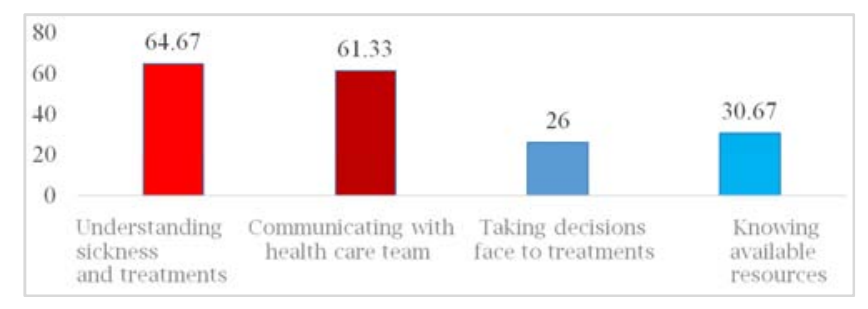

Figure 6. Distribution of patients according to the problems of information/communication dimension.

\subsubsection{Physical Dimension}

The figure 7 presents different preoccupations on physical dimension.

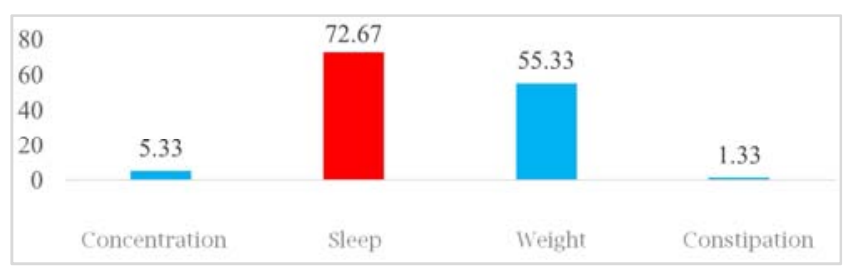

Figure 7. Distribution of patients with the problems of physical dimension.

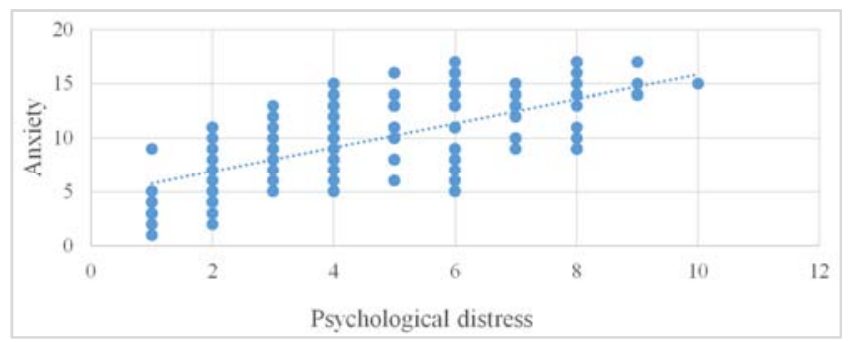

Figure 8. Positive correlation between the psychological scale and the HAD-A sub-scale.

\section{Correlation Between Scales}

The figure 8 shows a positive correlation between the analogical visual scale of psychological distress and the subscale of HAD-A with a coefficient correlation of Pearson (r) of 0.636 and a p-value (p) of 0.000 .

\subsection{Correlation Between the Psychological Distress Scale and the HAD-D Sub-scale}

The figure 9 shows a correlation between psychological distress scale and the HAD-D sub-scale with a coefficient correlation of Pearson (r) of 0.55 and a p-value (p) of 0.000 .

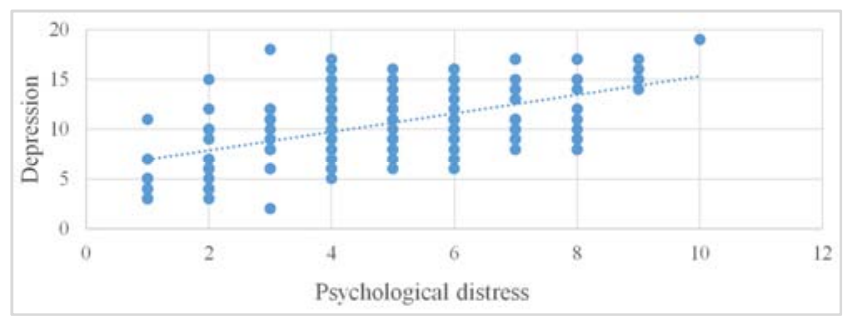

Figure 9. Positive correlation between the psychological distress scale and the HAD-D sub-scale.

\subsection{Correlation Between the Psychological Distress Scale and the Rosenberg Self-esteem Scale}

The figure 10 shows a positive correlation between analogical visual scale of psychological distress and the Rosenberg self-esteem scale with a coefficient correlation of Pearson (r) of -0.359 and a p-value (p) de 0.000 .

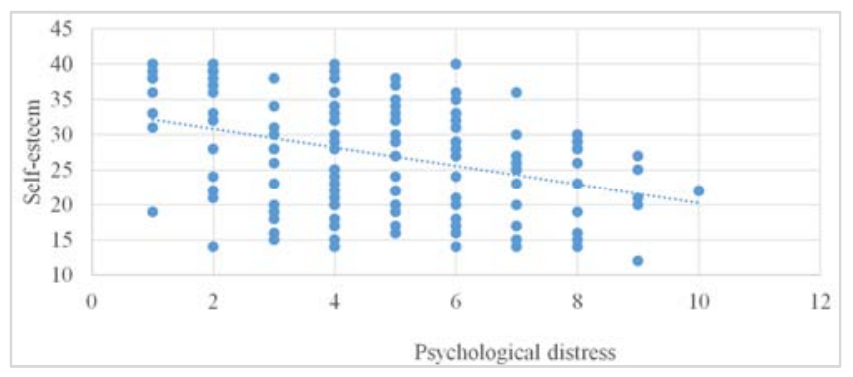

Figure 10. Negative correlation between the psychological distress scale and the Rosenberg self-esteem scale.

\subsection{Socio-demographical Characters}

The table 5 illustrates the socio-demographical analysis associated with the psychological distress of patients with breast cancer.

Table 5. Analysis by logistical regression of socio-demographical characters associated with the psychological distress.

\begin{tabular}{|c|c|c|c|}
\hline & \multicolumn{2}{|c|}{ Psychological distress } & \multirow[t]{2}{*}{ p-value } \\
\hline & Yes & No & \\
\hline & N $123(82 \%)$ & $\mathrm{N}=27(\mathbf{1 8 \%})$ & \\
\hline Gender & & & 0.592 \\
\hline Female & 117 & 27 & \\
\hline Male & 6 & 0 & \\
\hline Age group & & & 0.584 \\
\hline $20-39$ & 19 & 4 & \\
\hline $40-59$ & 83 & 17 & \\
\hline $60-79$ & 20 & 5 & \\
\hline$\geq 80$ & 1 & 1 & \\
\hline Profession & & & 0.834 \\
\hline With & 61 & 14 & \\
\hline Retired & 15 & 4 & \\
\hline Without & 47 & 9 & \\
\hline Socioeconomical level & & & 0.463 \\
\hline Down & 39 & 10 & \\
\hline Medium & 82 & 16 & \\
\hline High & 2 & 1 & \\
\hline Education & & & 0.32 \\
\hline Off school & 8 & 1 & \\
\hline Primary & 22 & 8 & \\
\hline Secondary & 56 & 8 & \\
\hline University & 37 & 10 & \\
\hline
\end{tabular}

\subsection{Clinical and Therapeutical Characters}

The table 6 presents the clinical and therapeutical characters associated with the psychological distress of patients with breast cancer. 
Table 6. Analysis logistical regression of clinical and therapeutical characters associated with the psychological distress.

\begin{tabular}{|c|c|c|c|c|c|c|}
\hline & \multicolumn{2}{|c|}{ Pathological distress } & \multirow{2}{*}{ OR gross (CI95\%) } & \multirow{2}{*}{ p-value } & \multirow{2}{*}{ OR adjusted (CI95\%) } & \multirow{2}{*}{ p-value } \\
\hline & Yes & No & & & & \\
\hline \multicolumn{7}{|c|}{ Antecedent } \\
\hline Yes & 43 & 10 & $0.91(0.382 .17)$ & $0.83 *$ & & \\
\hline No & 80 & 17 & 1 & & & \\
\hline \multicolumn{7}{|c|}{ Metastasis } \\
\hline Yes & 31 & 1 & & & & \\
\hline No & 92 & 26 & $0.11(0.010 .88)$ & & & $0.01 * *$ \\
\hline \multicolumn{7}{|c|}{ Chemotherapy } \\
\hline Yes & 105 & 23 & $1.01(0.393 .28)$ & $0.98^{*}$ & & \\
\hline No & 18 & 4 & 1 & & & \\
\hline \multicolumn{7}{|c|}{ Surgery } \\
\hline Yes & 15 & 3 & $1.11(0.304 .14)$ & $0.59 *$ & & \\
\hline No & 108 & 24 & 1 & & & \\
\hline \multicolumn{7}{|c|}{ Complication } \\
\hline Yes & 0 & 104 & & $0.01 * *$ & & \\
\hline No & 27 & 19 & & & & \\
\hline
\end{tabular}

** significant to $5 \%$ in gross analysis, * not significant to $5 \%$ in gross analysis; $\dagger \dagger$ significant to $5 \%$ in adjusted analysis, $\dagger$ not significant to $5 \%$ in adjusted analysis; (Confidence Interval) CI 95\%.

\subsubsection{Correlation, Medical Treatment Period and Psychological Distress}

The figure 11 illustrates a negative correlation between the psychological distress and the medical treatment period.

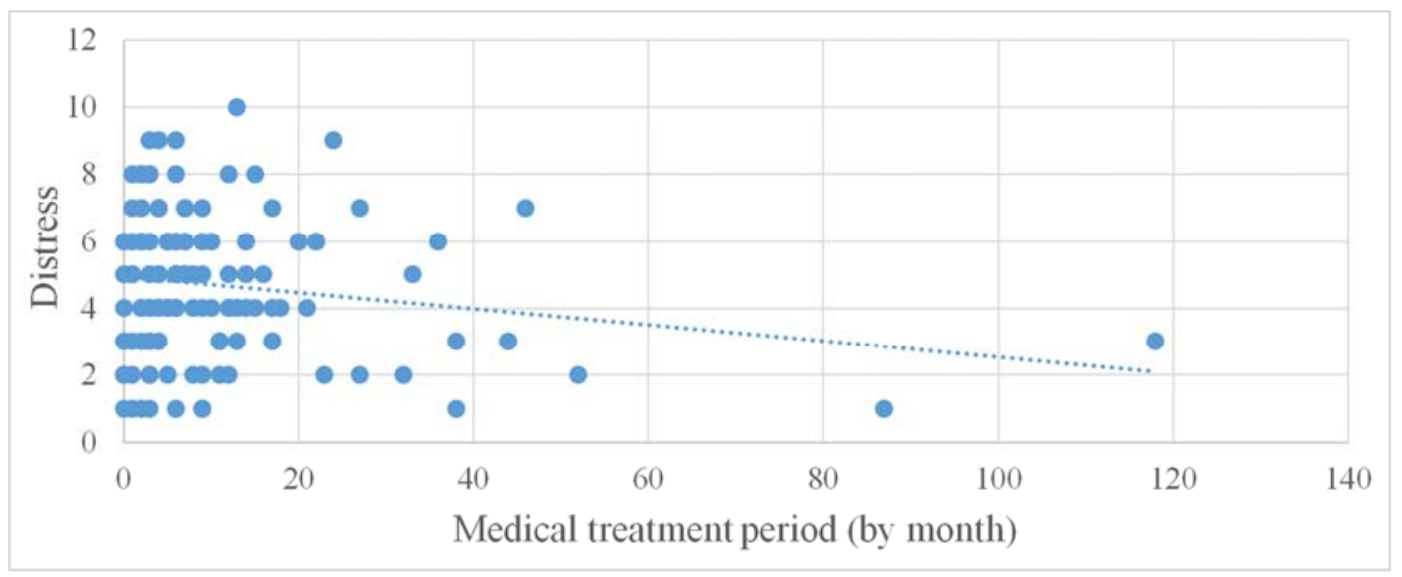

Figure 11. Cloud of points of distress in accordance with the medical treatment period.

\subsubsection{Correlation, Surgical Treatment Period and the Psychological Distress}

The figure 12 illustrates a negative correlation between the psychological distress and the post-surgical period.

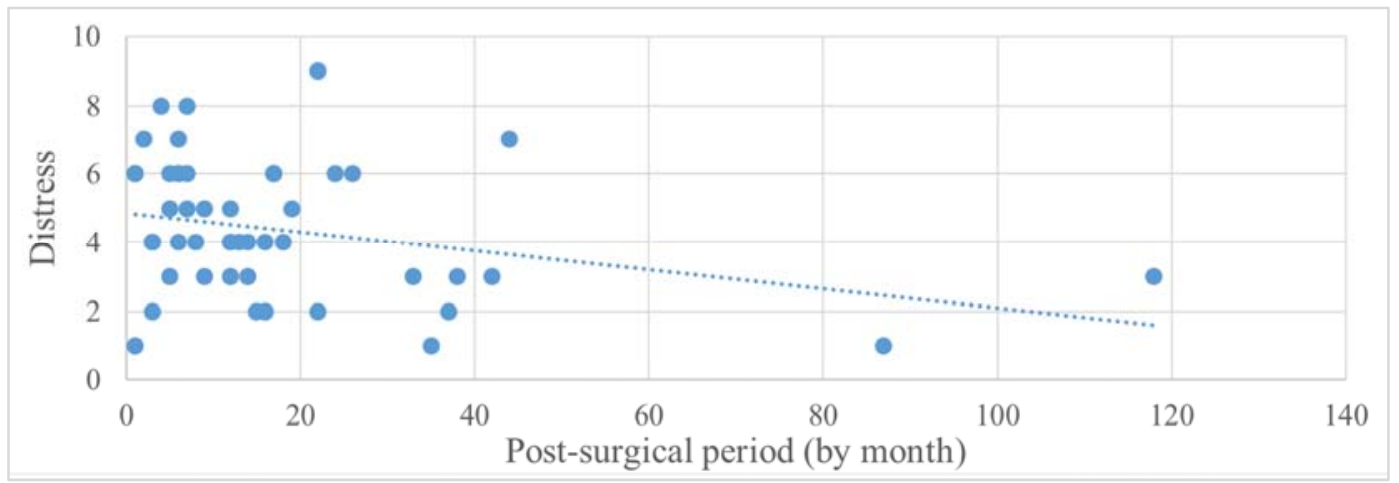

Figure 12. Cloud of points of distress in accordance with the post-surgical period. 


\subsection{Problems/Preoccupations}

The table 7 illustrates the analysis of problems/preoccupations, associated with the psychological distress of patients with breast cancer.

Table 7. Analysis by logistical regression of problems/preoccupations associated with the psychological distress.

\begin{tabular}{|c|c|c|c|c|c|c|}
\hline & \multicolumn{2}{|c|}{ Pathological distress } & \multirow{2}{*}{ OR gross (CI95\%) } & \multirow{2}{*}{ p-value } & \multirow{2}{*}{ OR adjusted (CI95\%) } & \multirow{2}{*}{ p-value } \\
\hline & Yes & No & & & & \\
\hline \multicolumn{7}{|c|}{ Problems/preoccupations } \\
\hline \multicolumn{7}{|c|}{ Practice } \\
\hline Yes & 123 & 23 & & $0.0008 * *$ & & \\
\hline No & 0 & 4 & & & & \\
\hline \multicolumn{7}{|c|}{ Spiritual } \\
\hline Yes & 118 & 24 & $2.95(0,66-13.18)$ & $0.15^{*}$ & & \\
\hline No & 5 & 3 & 1 & & & \\
\hline \multicolumn{7}{|c|}{ Social/family } \\
\hline Yes & 120 & 10 & $68(16.99-272.08)$ & $0.000 * *$ & & \\
\hline No & 3 & 17 & 1 & & & \\
\hline \multicolumn{7}{|c|}{ Emotional } \\
\hline Yes & 123 & 4 & & $0.0008 * *$ & & \\
\hline No & 0 & 23 & & & & \\
\hline \multicolumn{7}{|c|}{ Information } \\
\hline Yes & 120 & 20 & $14.0(3,34-58.68)$ & $0.0002 * *$ & $13.99(3,34-58.66)$ & $0.0003 \uparrow \dagger$ \\
\hline No & 3 & 7 & 1 & & & \\
\hline \multicolumn{7}{|c|}{ Physical } \\
\hline Yes & 108 & 16 & $4.95(1.93-12.65)$ & $0.0011 *$ & $4.95(1,94-12.65)$ & $0.0008 \dagger \dagger$ \\
\hline No & 15 & 11 & 1 & & & \\
\hline
\end{tabular}

$* *$ significant to $5 \%$ in gross analysis, * not significant to $5 \%$ in gross analysis; $\uparrow \dagger$ significant to $5 \%$ in adjusted analysis, $\uparrow$ not significant to $5 \%$ in adjusted analysis; (Confidence Interval) CI 95\%.

\subsection{Practice Dimension}

The table 8 illustrates the analysis of problems of practical dimension, associated with the psychological distress of patients with cancer.

Table 8. Analysis by logistical regression of problems of practice dimension associated with the psychological distress.

\begin{tabular}{|c|c|c|c|c|c|c|}
\hline & \multicolumn{2}{|c|}{ Pathological distress } & \multirow{2}{*}{ OR gross (CI95\%) } & \multirow{2}{*}{ p-value } & \multirow{2}{*}{ OR adjusted (CI95\%) } & \multirow{2}{*}{ p-value } \\
\hline & Yes & No & & & & \\
\hline \multicolumn{7}{|c|}{ Practice problems } \\
\hline \multicolumn{7}{|c|}{ Work/studies } \\
\hline Yes & 59 & 5 & $4.06(1,44-11.40)$ & $0.005 * *$ & $1.02(0,13-7.69)$ & $0.9870 \dagger$ \\
\hline No & 64 & 22 & 1 & & 1 & \\
\hline \multicolumn{7}{|c|}{ Finances } \\
\hline Yes & 123 & 22 & & $0.0001 * *$ & & \\
\hline No & 0 & 5 & & & & \\
\hline \multicolumn{7}{|c|}{ Joining the Meeting } \\
\hline Yes & 6 & 0 & & $0.59 *$ & & \\
\hline No & 117 & 27 & & & & \\
\hline \multicolumn{7}{|c|}{ Accommodation } \\
\hline Yes & 4 & 0 & & $1.00 *$ & & \\
\hline No & 119 & 27 & & & & \\
\hline
\end{tabular}

** Significant to $5 \%$ in gross analysis, * not significant to $5 \%$ in gross analysis; $\dagger \dagger$ significant to $5 \%$ in adjusted analysis, $\dagger$ not significant to $5 \%$ in adjusted analysis; (Confidence Interval) CI95\%

\subsection{Physical Dimension}

The table 9 illustrates the analysis of preoccupations of the physical dimension, associated with the psychological distress of patients with breast cancer. 
Table 9. Analysis by logistical regression of problems of physical dimension associated with the psychological distress.

\begin{tabular}{|c|c|c|c|c|c|c|}
\hline & \multicolumn{2}{|c|}{ Pathological distress } & \multirow{2}{*}{ OR gross (CI95\%) } & \multirow{2}{*}{ p-value } & \multirow{2}{*}{ OR adjusted (CI95\%) } & \multirow{2}{*}{ p-value } \\
\hline & Yes & No & & & & \\
\hline \multicolumn{7}{|c|}{ Physical problems } \\
\hline \multicolumn{7}{|c|}{ Concentration/memory } \\
\hline Yes & 7 & 1 & $1.57(0,19-13.31)$ & $1.000^{*}$ & & \\
\hline No & 116 & 26 & 1 & & & \\
\hline \multicolumn{7}{|c|}{ Sleep } \\
\hline Yes & 95 & 14 & $3.15(1.33-7.48)$ & $0.0074 * *$ & $0.42(0.06-3.17)$ & $0.4011 \dagger$ \\
\hline No & 28 & 13 & 1 & & 1 & \\
\hline \multicolumn{7}{|c|}{ Weight } \\
\hline Yes & 74 & 9 & $3.02(1.26-7.27)$ & $0.0111 * *$ & $2.07(0,27-15.87)$ & $0.4848 \dagger$ \\
\hline No & 49 & 18 & 1 & & 1 & \\
\hline \multicolumn{7}{|c|}{ Constipation/diarrhea } \\
\hline Yes & 1 & 1 & $0.21(0.01-3.52)$ & $0.3285^{*}$ & & \\
\hline No & 122 & 26 & 1 & & & \\
\hline
\end{tabular}

** significant to $5 \%$ in gross analysis, * not significant to $5 \%$ in gross analysis; $\dagger \dagger$ significant to $5 \%$ in adjusted analysis, $\dagger$ not significant to $5 \%$ in adjusted analysis; (Confidence Interval) C195\%

\section{Methodology Analysis}

We performed a transversal analytical hospital study with the aim to assess the psychological distress of patients with breast cancer.

This methological choice justified the necessity to know how the breast cancer, the frequent pathology, chronic, and difficult to live by its therapeutical heaviness which affects the psychological dimension of patients.

In our environment, this study is difficult with population, our choice was based on hospital study allowing to recruit patients followed in the service.

Among all the quiz on distress in carcinology, our choice was on the psychological distress scale, the list of the associated problems, the HAD, together with the Rosenberg self-esteem scale.

In addition, this choice justified the fact that its scales are specifics to the assessment of the psychological sphere to the cancerous patients, and were translated in national languages.

Study Limit

a) the sample size and the mono-centric character making difficult all exploitation of results to the general population;

b) the patients recruitment in hospital milieu, or all cases of breast cancer are not listed, since all sick persons do not consult due to the high price of therapeutical management;

c) all the scales were used without validation and adaptation to the Congolese population. The translation into national languages made easily the administration to off school patients.

Despite these limits, we got the results which can be debated with the literature data in order to valorize this work.

\section{Discussion}

\subsection{Socio-demographical Aspects}

The middle age of our study was $50.14 \pm 10.75$ years with the extremes from 21 to 82 years. The most represented age group of patient was from 36 to 51 years $(42.00 \%)$. Our results were similar to those reported in the literature by Toure and al [6], Mimouni and al [7] reported a middle age near of our study, respectively: 50 years, 50.7 years.

In the industrialized countries, the middle age seems to be tardy, according to Méry and al [2] study, the middle age was 61 years for the patients with breast cancer. The breast cancer is the most common to the woman in the world according to the WHO, and with the minimal percentage in the male population estimated at $1 \%$ in the word $[2,8]$.

\subsection{Clinical and Therapeutical Characters}

The most of our patients $(88.6 \%)$ were presented in consultation for "breast nodule". Our results were corroborated with those of Sando and al [9] which reported $92.4 \%$ of patients in consultation for "breast nodule; with Komboigo et al [10] who noted that "breast nodule" is the first rank about the consultation with a frequency of $27.6 \%$.

More of the half of patients $(54 \%)$ were diagnosed at an enough advanced stage of sickness (T3 and T4). This could be explained by the therapeutical itinerary took by the patients before the first consultation at the hospital.

These results are comparable to those of Komboigo and al [10] who reported that 46.6 of patients were diagnosed at a very advanced stage (T3); with Sando et al [9] reported in their study $54.2 \%$ of patients were diagnosed at stage T4. In contrast B, Méry and al [2], on a cohort of 277 patients, $68 \%$ of patients were diagnosed at an early stage (T1). This difference could be explained in fact that the patients come in consultation at an early stage of the sickness in the industrialized countries contrary in our country.

\subsection{Distress in Oncology}

With the diagnosed persons of cancer and their neighbors is common and this distress is variable all along cares trajectories [4]. Near of the half diagnosed persons and their neighbors feel such distress with significant manner. The distress is a health indicator which has been for longtime ignored by the patricians. Thanks to scientifical progress and medical progress, more of $60 \%$ persons with cancer survive to their sickness. It is 
frequent to meet people with a metastatic cancer who live many years with their sickness. Now, cancer is a chronic sickness $[4,11]$. Because many people live with harmful effect of treatments or of their sickness [4].

According to Rivest and all [4], the distress is the sixth vital sign of persons affected by the cancer, after the beating, the blood pressure, the temperature, rate of respiration and the pain. The systematical detection of the distress, now known as a practical standard in cancerology, constitute probably the most used means to detect the non-filled needs of patients affected by cancer $[4,11]$.

The recent searches revealed that an important proportion of people with cancer presenting a significant distress are neither yet oriented toward services nor treated for their distress or their mental trouble health $[13,14]$ In the literature, the prevalence of the distress is variable in the studies regarding different reasons, which the tumoral seat, the sickness stage, the gender, the socioeconomical status [15]; this variation also depends on the type of version of the used scale.

In our study, more of $80 \%$ of patients presented a psychological distress, this could be explained in fact that the majority of our patients $(90.67 \%)$ did not benefit a management in psycho-oncology during the ongoingly cares, then the half of our patients were diagnosed at an advanced stage of sickness.

However, the prevalence in our study was upper in comparison to other studies of some authors just like Tremblay and $a l$ [12], Méry and al [2] with Dolbeault [5] who reported prevalence respectively in order of: $33.9 \% ; 41 \%$ and $51.3 \%$. Furthermore, our results were close from those of Howell and al [1] who reported a prevalence of $70 \%$.

The problems expressed by the patients were regrouped in six dimensions: practice, socials, emotional, spirituals, informational and physical. All the categories of problems in our study were of an upper prevalence of $80 \%$.

In the same way, the affected women by breast cancer constitute another vulnerable group to the distress all along of ongoingly cares $[4,11]$.

The recent studies assess that $40 \%$ of patients with cancer will do the experience of an important distress because of the cancerous sickness [1].

Our results are close from those of Tremblay and al [12] who reported the emotional categories at the first rank, after the physical category with the respective prevalence of $74.6 \%$ and $64 \%$. About the spiritual category, this one was in the last position contrarily in our study where it was in the $3^{\text {rd }}$ rank; this could be explained in fact that all our patients had religious belief (96\%).

\section{a) Anxiety and depression}

All most three quarters (74\%) of patients had an upper score at 7 ; and almost of the half of patients (74\%) of patients presented anxious trouble. This could be explained in fact that the most patients were seen at an advanced stage of sickness (T3, T4), with a bad prognosis (SBR II) then, the majority of patients had not management in psychooncologic all along the cares trajectories due to the lack of a device of the management of supportive cares.

However, some authors like C. Perdrizet-Chevalier and al [16], Dolbeault [17], and Tremblay and al [12] reported prevalence respectively from $30 \% ; 26.7 \%$ and $26.6 \%$. In the same way in our sample $(79.43 \%)$ had a greater than or equal to 7 of patients presented a depression. Other series, $[12,16$, 17] were reported prevalence of $32 \% ; 11.4 \%$ and $9.4 \%$.

The self-esteem or the body image is an important element to take with consideration in the management of the woman with breast cancer, a major interest is at the search of the body image in mammary oncology these last years [18-20].

The trouble prevalence of the body image is variable in the literature according to the moment chosen for the screening. This variability can be explained with the use of different measure tools, the divergence of populations studied and by type of studied treatment [18].

In our study, $38 \%$ of patients had very weak self-esteem, needing a psycho-oncologic intervention.

Our results are comparable to those found by Falk Dahl [18] who found a prevalence $30.6 \%$. Besides, some authors like [1921 ], found respectively the prevalences: $45 \% ; 47,6 \%$ et $58 \%$.

b) Associated factors with the psychological distress.

The association between the age and the psychological distress during the breast cancer seems to be controversial. In our series, there was not association between the age and the arisen of pathological distress.

This could be explained by the small size of ours ample. Many authors like Härtl and $a l$ [22] and Turner and al [23]; Bardwell and $a l$ [24] have mentioned that the young patients with breast cancer showed more psychological distress than the eldest patients.

c) The stage of disease

According to Vachon and al [25] the progression of the disease leads first to the appearance then to the interview of the psychological distress. Also, the distress is variable according to the type of cancer, the elapsed time from the diagnosis and the stage of disease.

In fact, several studies showed that the cancerous patients having metastasis from a distance had a deep psychological distress than those who were in localized stage or loco-regional [26]. In 2016 Jacob and al [27] lead a study with the objective a significant association between the metastatic stage of breast cancer and the arisen of the psychological distress.

Thus, we found a significant association between the lack of metastasis and the psychological distress. We can affirm in fact that the lack of metastasis was a protector factor of the arisen of the psychological distress.

\section{d) Factor within treatments}

Concerning the chemotherapy in the long term, it can cause an alteration of life quality with the arisen of the psychological distress. In fact, in our series Hopwood and al [28]. Noticed an increase of the prevalence and the severity of psychological distress to the women following a chemotherapy. In this context, the lack of the radiotherapy would be also an aggravating factor of distress.

Feelings of "ghost breast" often being painful, were described to the mastectomized women $[27,28]$. In our series, although we did not find a significant association between the surgical treatment and the arisen of the psychological distress, we nevertheless found a negative correlation between the post- 
surgical period and the arisen the psychological distress.

\section{e) Factor within problems faced}

The social backing is known to play an important role in the psychological and physical adjustment to the disease [29]. The company quality is crucial factor in the arisen of the psychological distress. In fact, the more the patient will not be able to communicate his/her anxieties, the more he/she will feel isolated and the more he/she will be affected by the psychological distress [30]. The neighbors assure an important psychological back-up, they imply in the management and they go along with the patient all along of his/her medical course $\mathrm{p}<0.001 ; \mathrm{OR}=5.49 \mathrm{p}<0.001 ; \mathrm{OR}=0.85 \mathrm{p}<0.001$ ).

Furthermore, Berhili. S and al [30] reported that the lack of social back-up was the second factor associated to psychological distress $\mathrm{OR}=5.33$ [2.62-10.82]; $\mathrm{p}<0.001$. In our study, we found a significant link between the problems of social order and the arisen psychological distress.

\section{f) Communication/information and physical dimension}

In our study, a statistically link was found between the problems of communication or information on the sickness and arisen psychological distress. The somatical manifestations of breast cancer can have the aftereffects on the psychological state of patient. Thus, some authors, Perdrizet-Chevalier and al [16] were reported that the problems of physical order were predictive of the psychological distress. In our study, a significant association was found between the physical order and the arisen psychological distress.

In the other hand, the studies of Burgess and al [29] did not have a significant association between the physical order of breast cancer and the arisen psychological distress.

\section{Conclusion}

As all other chronical sickness, the breast cancer has aftereffects on all dimensions (physics, spiritual, psychologic, social, economic) of the one with this affectation. A prevalence to $82 \%$ was associated with many factors, as: the metastatic stage of breast cancer; the appearance of secondary effects (therapeutical complication); the problems of social order, physics, spiritual, emotional and communicational. A psychological back-up of patients with breast cancer in the service of medical oncology is useful to decrease the prevalence of this distress.

\section{References}

[1] Howell D, Keshavarz H, Esplen MJ, Hack T, Hamel M, Howes J, Jones J, Li M, Manii D, McLeod D, Mayer C, Sellick S, Riahizadeh S, Noroozi H, \& Ali M. On Behalf of the Cancer Journey Advisory Group of the Canadian Partnership Against Cancer. A Pan Canadian Practice Guideline: Screening, Assessment and Care of Psychosocial Distress, Depression, and Anxiety in Adults with Cancer. Toronto: Canadian Partnership Against Cancer and the Canadian Association of Psychosocial Oncology. Repéré à http://www.capo.ca/wpcontent/uploads/2010/10/Distress_guid eline_CAPO_2015;07311.pdf.
[2] Méry B, Froissart G-D, Vallard A, Lallich S, Espenel S, Jouan $\mathrm{S}$, et al. Dépistage de la détresse psychologique chez les patientes en cours de traitement du cancer du sein. Bulletin $d u$ Cancer. 2015; 102 (10): 845-53.

[3] Howard-Anderson, J., Ganz, P. A, Bower, J. E. et Stanton, A. L. (2012). Quality of life, fertility concerns and behavioral health outcomes in younger breast cancer survivors: A systematic review. Journal of National Cancer Institute, 104 (5), 386-405.

[4] Rivest J. Détresse des personnes atteintes de cancer: un incontournable dans les soins [Internet]. Place of publication not identified: Santé et services sociaux Québec; 2017 [cité 13 juill 2019]. Disponible sur: http://deslibris.ca/ID/10092432.

[5] Dolbeault S, Dauchy S, Brédart A, Consoli SM. La psychooncologie. John Libbey Eurotext; 2007.

[6] Toure M, Nguessan E, Bambara AT, Kouassi YKK, Dia JML, Adoubi I. Facteurs liés au diagnostic tardif des cancers du sein en Afrique-sub-saharienne: cas de la Côte d'Ivoire. Gynécologie Obstétrique \& Fertilité. 2013; 41 (12): 696-700.

[7] Mimouni M, Chaouki W, Errihani H, Benjaafar N. Analyse des délais de traitement du cancer du sein : expérience d'un centre de référence tertiaire au Maroc. Bulletin $d u$ Cancer. 2018; 105 (9): 755-62.

[8] Bray F, Ferlay J, Soerjomataram I, Siegel RL, Torre LA, Jemal A. Global cancer statistics 2018: GLOBOCAN estimates of incidence and mortality worldwide for 36 cancers in 185 countries. CA: a cancer journal for clinicians. 2018; 68 (6): 394-424.

[9] Z Sando, J Tsuala Fougue, F Ymele Fouelifack, J H Fouedjo, E. T. Mboundou, J L Oyono Essame. Profil de cancers gynecologiques et mammaires à Yaoundé- Cameroun. Pan African Medical 2014; 17; 28 at: http://www.panafricanmedjournal.com/content/article/17/28/full.

[10] Komboigo BE. Pathologies mammaires dans le service de gynécologie du Centre Hospitalier et Universitaire Yalgado Ouedraogo: épidémiologie, diagnostic et pronostic. journal de la SAGO (Gynécologie-Obstétrique et Santé de la Reproduction). 2017; 2 (18).

[11] Rivest J, Desbaumes Jodoin V, Leboeuf I, Folch N, Martineau J. T., Beaudet-Hillman, Tremblay. Les patients partenaires dans les soins du cancer: une stratégie novatrice dans le dépistage de la détresse. Can Oncol Nurs J. 2020 Summer; 30 (3): 186-192.

[12] Tremblay N, Roy O., Compagna L, Provencher C. Dépistage systématique de la détresse: portraits et regards croisés sur les perceptions des différents acteurs, perspectives cliniques et de recherche. Communication présentée à la conférence annuelle CANO-ACIO 2015, Toronto, Ontario.

[13] J Zabora ${ }^{1}$, K BrintzenhofeSzoc, B Curbow, C Hooker, S Piantadosi The prevalence of psychological distress by cancer site. Psychooncology. 2001; 10 (1): 19-28.

[14] Mitchell, A. J., Meader, N., Davies, E., Clover, K., Carter, G. L., Loscalzo, M., \& Zabora, J., Meta-Analysis of Screening and case Finding Tools for Depression in Cancer: EvidenceBased Recommendations for Clinical Practice on Behalf of the Depression in Cancer Care Consensus Group. Journal of Affective Disorders, 2011: 140 (2), 149-60.

[15] Fitch, M. I. Screening for Distress: A Role for Oncology Nursing. Current Opinion in Oncology, 2011: 23 (4), 331-7. 
[16] Perdrizet-Chevallier C, Reich M, Lesur A. Dépression et anxiété chez les femmes souffrant de cancers gynécologiques. Annales Médico-psychologiques, revue psychiatrique. 2008; 166 (4): 292-6.

[17] Dolbeault S. La détresse des patients atteints de cancer: prévalence, facteurs prédictifs, modalités de repérage et de prise en charge. [PhD Thesis]. 2009.

[18] Falk Dahl, C. A., et al., A study of body image in long-term breast cancer survivors. Cancer, 2010. 116 (15): p. 3549-3557.

[19] Rhondali W, Chisholm GB, Filbet M, Kang D-H, Hui D, Cororve Fingeret $\mathrm{M}$, et al. screening for body image dissatisfaction in patients with advanced cancer: a pilot study. Journal of palliative medicine. 2015; 18 (2): 151-156.

[20] E Faten, M Nader, H Raies, M Sana, M Amel, M Fadhel. Le trouble de l'image du corps chez 100 femmes tunisiennes atteintes d'un cancer du sein. Bulletin du Cancer, 2018; 86 (5): 240-255.

[21] Reich, M., Cancer et image du corps: identité, représentation et symbolique. L'Information psychiatrique, 2009. 85 (3): $p$. 247-254.

[22] Härtl, K., et al., Quality of life, anxiety, and oncological factors: a follow-up study of breast cancer patients. Psychosomatics, 2010. 51 (2): 112-123.

[23] Turner, J., et al., Psychosocial impact of newly diagnosed advanced breast cancer. Psycho-Oncology, 2005. 14 (5): p. 396-407.
[24] Bardwell, W. A., et al., Objective cancer-related variables are not associated with depressive symptoms in women treated for early-stage breast cancer. Journal of Clinical Oncology, 2006. 24 (16): p. 2420-2427.

[25] Vachon, M. Psychosocial distress and coping after cancer treatment. Cancer Nursing, 2006. 29 (2 Suppl.), 26-31.

[26] Ciaramella, A. and P. Poli, Assessment of depression among cancer patients: the role of pain, cancer type and treatment. Psycho-Oncology, 2001. 10 (2): p. 156165.

[27] L Jacob, L Bleicher, K Kostev, M Kalder. Prevalence of depression, anxiety and their risk factors in German women with breast cancer in general and gynecological practices. Journal of cancer research and clinical oncology, 2016; 142 (2): $447-452$.

[28] P Hopwood, G Sumo, Judith Mills, J Haviland, J M Bliss. The course of anxiety and depression over 5 years of followup and risk factors in women with early breast cancer: results from the UK Standardisation of Radiotherapy Trials (START). The breast. 2010; 19 (2): 8491.

[29] C Burgess, V Cornelius, S Love, J Graham, M Richards, A Ramirez. Depression and anxiety in women with early breast cancer: five year observational cohort study. Bmj. 2005; 330 (7): 117-125.

[30] S Berhili, S Kadiri, M Benoulaid, A Aissa, E Ogandaga, S El Majjaoui et al. Quelle est la valeur du soutien familial dans la survenue de la détresse psychologique chez les patientes suivies pour cancer du sein?. Cancer/Radiothérapie. 2016; 20 (6-7): 722 . 